Check for updates

London, UK

Cite this as: BMJ 2021;375:n2431 http://dx.doi.org/10.1136/bmj.n2431 Published: 04 October 2021

\section{Complaints about politicians' use of statistics rise sharply}

\section{Adrian O'Dowd}

Statistics experts have questioned politicians' and civil servants' use of data dozens of times over the past year as complaints about how statistics are used have almost tripled in 12 months.

The UK Statistics Authority dealt with 323 pieces of casework between 1 April 2020 and 31 March 2021, almost three times the 109 cases it had the previous year, said the watchdog in its annual report. ${ }^{1}$

Most ( $72 \%$ ) of the 323 cases this year related to health and social care, with $97 \%$ of those related to the covid-19 pandemic, said the report, which was produced with the authority's regulatory arm, the Office for Statistics Regulation.

The greatest proportion and more than half (53\%) of the 323 cases came from members of the public, which was a substantial increase on the $27 \%$ of cases from the public in 2019-20. The remainder came from other sources including academia, the media, parliament, local government, and internally.

During the year, authority chair David Norgrove wrote publicly to parliamentarians on 12 occasions relating to nine separate interventions. These were sent to five members of parliament, four members of the Scottish parliament, and one member of the Senedd, although the latter related to an intervention in the previous year.

The official figures show that the authority published 47 formal responses to complaints raised during the year.

In one of the cases, the regulator wrote to Matt Hancock, at the time secretary of state for health and social care, about his claims that the government had capacity to provide 200 ooo covid-19 tests per day saying that his figures were still "far from complete and comprehensible" and that the testing statistics still fell well short of standards.

In another case, the regulator wrote to the Scottish first minister Nicola Sturgeon about her claims that the prevalence of covid in Scotland was five times lower than elsewhere in the UK, saying the sources she had used to make the claim did "not allow for a meaningful comparison to be made.”

The authority, which monitors and safeguards the production and publication of official statistics, said for the year in question the category with the highest number of problems raised was the "quality, reliability, and trustworthiness of statistics" which represented 156 cases (48\%).

The next most common category, and the most common in the previous year, was about the "use or misuse of statistics" which accounted for 74 cases (23\%).

Ed Humpherson, director general for regulation and head of the Office for Statistics Regulation, said, "Our casework function is central to our role in upholding statistics that serve the public good. This year's report, set against the backdrop of the pandemic, illustrates how crucial our work is in protecting the role of statistics in public debate."

Stian Westlake, chief executive of the Royal Statistical Society, said, "The work of statisticians has been incredibly important in helping us to understand and control the pandemic. The Office for National Statistics and bodies like Public Health England have done a sterling job in rapidly building a covid stats infrastructure that is widely praised around the world.

“The rise in casework shows, however, that this isn't always easy. It's good to see the Office for Statistics Regulation stepping in when statistics are misused, for example during last summer's exams fiasco when they responded to a call from us to review Ofqual's use of algorithms."

UK Statistics Authority, Office for Statistics Regulation. Annual review of UK statistics authority casework 2020-21. 30 September 2021. https://uksa.statisticsauthority.gov.uk/wp-content/uploads/2021/09/AnnualReview-of-UK-Statistics-Authority-Casework-2020-21.pdf. 